and peripherally in an irregular manner. When last seen the body remained in all appearance exactly like an ordinary Laveran body. The drawing was made by Dr. Burrows at the time and represents some of the changes which he saw the body undergo. If this is the natural evolution of the Laveran body it is clear that it cannot be a parasite. I am, Sirs, yours truly,

E. I. PAYNF

Secunderabad. Surgeon-Lieutenant, 5th M.I.

\section{"RHEUMATIC DILATATION OF THE HEART."}

\section{To the Editors of THE LANCWT.}

SiRs,-In reply to Dr. Lees's letter on this subject in THв LANCET of July 25th I should like entirely to endorse his opinion with regard to the frequency, if not the invariability, of dilatation of the heart in acute and sub-acute attacks of rheumatism. I have seen a case where the left cardiac margin extended to the axillary line, and since practising the Nauheim treatment I have not seen a case of rheumatic ferer without some dilatation of the heart. I have further observed (with a mathematically accurate method of percussion) that cardiac dilatation obtains in all cases of bigh temperature. A systolic bruit is very frequent in cases of pure dilatation, the bruit disappearing when the dilatation is reduced-vide Case 5 in my paper on the Schott Methods for the Treatment of Chronic Affections of the Heart in THE LAXCET of March 21st, 1896, where the bruit disappeared in half an hour. With improved methods we are on the verge of extraordinary discoveries of the capability of the heart for dilatation. Recently I had an opportunity of percussing the heart of a patient immediately after a severe fright and found the left cardiac boundary exceeding the normal by three inches, and the dilatation extended upwards as near the jugular fossa as possible, causing violent palpitation and a feeling of suffocation, the heart returning to its normal boundary in half an hour.

I am, Sirs, yours faithfully,

Loyer Seymour.street, W., July 26th, 1896

ERNEST KTNGSCOTE.

\section{A CASE OF OVARIAN PREGNANCY.}

To the Editors of THE LANCET.

SIRs,-I have read with great interest Dr. Oliver's case of otarian pregnancy published in THE LANCET of July 25th. The writer states that " the tumour, which was the right ovary, was found to be a closed sac containing a fullgrown foetus with its cord and placenta. ...... No breach in the right Fallopian tube could be detected either at the time of operation or afterwards." I trust that so valuable a specimen will be skilfully mounted and carefully preserved. It appears to be an instance of ovarian pregnancy, but eridence is wanting that the ovary was the primary seat of the abnormal gestation. Allow me to refer Dr. Oliver to some notes which I published in the Transactions of the Obstetrical Society, vol. xxxv., 1893, p. 222, entitled

"Fotus in Peritoneal Cavity: Question of Abdominal Gestation, with a Summary of Reported Cases of Primary Abdominal and Ovarian Pregnancy." Dr. A. Beale's case, on which the notes were founded, is very instructive. The foetus lay on the broad ligament close to the tube, whence it had probably been shed. I noted (p. 232) that Dr. Lusk attached little credit to cases where the tubes are reported as intact and not in communication with the sac. I further observed that the theory that the fimbrix might retract from an ovum developed in the ostium was supported by the high authority of Iraun of Vienna, who observed that when the ovum developed in the outer part of the tube the membranes might project freely from the ostium and contract adhesions to the surrounding structures, the ovary, for example. Further development would lead to the evident source of fallacy indicated by Lusk. Thus in an advanced case like Dr. Uliver's it is impossible to prove that the ovary was the primary seat of the pregnancy. In four out of the five cases of alleged primary ovarian pregrancy which I analysed gestation was more or less artanced. I concluded by showing that we cannot wid Irimary orarian pregnancy as proved until some obcrever can demonstrate a minute fotus lodged in a sac entirely inside the ovary, just as we so often detect a very early ovum entirely inside the tube. Such a specimen has not been satisfactorily demonstrated, whilst early tubal pregnancy is familiar to us all. Hence it is more probable that the foetus in Dr. Oliver's case developed originally in the tube and escaped after the fashion indicated by Braun, than that it was from the first an inhabitant of the adjacent ovary.

If primary ovarian pregnancy be possible, how is it that we do not meet with hæmatoceles destroying the ovary at an early stage of gestation? This accident is very frequent in tubal sacs. I published in THE LANCET' ${ }^{1}$ four cases which came under my own care within four months. Yet an early ovum in the ovary would be poorly protected and very liable to burst. The grafting of an older ovum with strong membranes on the surface of the ovary is not difficult to understand. I am, Sirs, yours faithfully,

Granville-place, W., July 25th, 1896.

ALBAN DORAN.

\section{"THE MILDER VARIETIES OF APPEN. DICITIS."}

To the Editors of THE LANCET.

SIRs,-The views of a surgeon on medical treatment are always interesting but sometimes misleading. In an address under the above title published in THE LANCET of July 25th Mr. W. Arbuthnot Lane has laid down some rules for the treatment of appendicitis. He says: "In the mild forms the regulation of the functions of the intestines by means of the suitable combination of drugs already indicated (strychnia belladonna, and aloes) is sufficient to relieve the patient of further recurrences. If the attack is very painful give morphia to allay the pain, keep the patient perfectly quiet, and if you suspect any loading of the large bowel give a large enema. If the pain, vomiting, and general disturbance are great give morphia in sufficient quantity to keep the patient thoroughly under its influence," Of course Mr. Lane is aware that the disastrous results of thus drugging the patient with morphia and concealing all symptoms, more especially those pointing to the necessity for surgical interference, have led many physicians to discontinue the use of the drug entirely in this affection. But, further, if the attack of appendicitis follows the ingestion of a heavy meal, as is not uncommon, the effect of morphia in causing the retention of a large amount of undigested material in the bowel will tend to aggravate the inflammation. In consequence of the recognition of this fact physicians have been led to employ an evacuant treatment by salines, \&c., and thus frequently to cut short an attack. This treatment, although it may not fit in with Mr. Lane's theory of fxcal pellets popping in and out of the appendix, will be found serviceable in many of "the milder varieties of appendicitis." I am, Sirs, yours faithfully,

Old Cavendish-street, W., July 27th, 1896.

G. A. Suthertand,

\section{MIDWIVES REGISTRATION.}

\section{To the Editors of THE LANOET.}

S1Rs, - I enclose a copy of some correspondence which, as it refers to a matter of importance to the profession, I shall be glad if you can publish.

Hatfield, Herts, July 26th, 1896.

I am, Sirs, yours faithfully,

LOYELL DRAGE.

" Hatfield, Herts, July 21st, 1896

"SIR,-I have the honour to place the resignation of my member ship of the Council of the Obstetrical Society in your hands. Thi course, which, in view of the honour which the Fellows of the Society conferred upon me by their selection, I now take with much regret, would have been adopted by me earlier had it not been my conviction that in view of $\mathrm{my}$ opinions upon the questions of the prevention of puerperal fevers and the registration of midwifery nurses it was my duty to do what lay in my power to modify what have since been universally recognised as ill-considered measures, rather than to take the easier steps of avoiding my share of the discussion and the disagreeable necessity of opposition. In January 1891, a discussion on the Principles of the Midwives Registration was instituted by the Council, but no indications of anv details of legislative measure were given and discussion was therefore truitless. Since that time, however, a Bill for the Midwives Registration bas been introduced in the Houses of Pariament and the Council has taken steps to further the progress of that Bill. Now I have protested against the taking part of a scientific society whose organisation is unfitted for political discussion in a matter of politics. I have urged the impropriety of the action of the Council in taking steps to further the progress of a Bill when

1 ThE J A NCET, March 28th, 1896, p. 836. 